\title{
A Pedagogia da Autonomia e o ensino de Matemática
}

\author{
Jocinéia Medeiros ${ }^{1}$, Marcos Lübeck ${ }^{2}$, Graciela Siegloch Lins ${ }^{3}$, Fernando Luiz Andretti ${ }^{4}$
}

\begin{abstract}
Resumo
Por ser comum ouvir comentários negativos relacionados à Matemática é que se torna essencial a busca por processos de ensino e aprendizagem que deem sentido aos conteúdos matemáticos curriculares, de maneira a mudar esses juízos e a proporcionar aos educandos desenvolverem mais gosto por essa disciplina. Nesse aspecto, os conhecimentos sobre os saberes necessários à prática educativa, do livro Pedagogia da Autonomia de Paulo Freire, contribuem para um pensar, no caso da Matemática, mais humanizado, ou seja, em uma Matemática contextualizada dentro da realidade vivida pelos educandos. Dessa forma, este texto tem por finalidade apresentar um relato de experiência de uma atividade matemática, utilizando a teoria desse pensador com alunos do $5^{\circ}$ ano do Ensino Fundamental I, de uma escola municipal de Foz do Iguaçu, Paraná. Seu tema envolveu o cálculo de impostos embutidos numa compra de supermercado e a metodologia usada seguiu preceitos da pesquisa-ação. Este trabalho mostrou-se bastante relevante por apresentar uma compreensão de que é muito importante vincular os conteúdos matemáticos curriculares com a realidade do educando e por problematizar esses conteúdos nas suas relações sociais, políticas e econômicas, e assim desenvolver a consciência crítica dos envolvidos sobre a sua presença no mundo.
\end{abstract}

\section{Palavras-chave}

Impostos. Ensino. Matemática. Paulo Freire. Prática educativa.

\footnotetext{
${ }^{1}$ Mestra em Ensino pela Universidade Estadual do Oeste do Paraná, campus Foz do Iguaçu, Brasil; assistente em administração na Universidade Federal da Integração Latino-americana, Paraná, Brasil. E-mail: jo4medeiros@gmail.com.

2 Doutor em Educação Matemática pela Universidade Estadual Paulista Júlio de Mesquita Filho, campus Rio Claro, São Paulo, Brasil; professor adjunto da Universidade Estadual do Oeste do Paraná, campus Foz do Iguaçu, Brasil. E-mail: marcoslubeck@gmail.com.

${ }^{3}$ Mestra em Ensino pela Universidade Estadual do Oeste do Paraná, campus Foz do Iguaçu, Brasil; professora da rede estadual de educação de Foz do Iguaçu, Paraná, Brasil. E-mail: graciela.siegloch@gmail.com.

${ }^{4}$ Mestre em Ensino pela Universidade Estadual do Oeste do Paraná, campus Foz do Iguaçu; professor da rede municipal de educação de Foz do Iguaçu, Paraná, Brasil. E-mail: fernando_andretti@ hotmail.com.
} 


\title{
The Pedagogy of Autonomy and the teaching of Mathematics
}

\author{
Jocinéia Medeiros $^{5}$, Marcos Lübeck ${ }^{6}$, Graciela Siegloch Lins ${ }^{7}$, Fernando Luiz Andretti ${ }^{8}$
}

\begin{abstract}
Because it is common to hear negative comments related to mathematics, it is essential to search for teaching and learning processes that give meaning to curricular mathematical content, in order to change these judgments and provide learners with more taste for this discipline. In this respect, the knowledge about the knowledge necessary for the educational practice of Paulo Freire's book Pedagogy of Autonomy contributes to a more humanized thinking, in the case of mathematics, that is, in a contextualized mathematics within the reality lived by the students. Thus, this text aims to present an experience report of a mathematical activity, using the theory of this thinker with students of the 5th grade of Elementary School, from a municipal school in Foz do Iguaçu, State of Paraná, Brazil. Its theme involved the calculation of taxes embedded in a supermarket purchase and the methodology used followed the precepts of action research. This work was very relevant because it presents an understanding that it is very important to link the curricular mathematical contents with the reality of the student and to problematize these contents in their social, political and economic relations, and thus develop the critical awareness of those involved about your presence in the world.
\end{abstract}

\section{Keywords}

Taxes. Teaching. Mathematics. Paulo Freire. Educational practice.

5 Master in Teaching, State University of Western Paraná, Foz do Iguaçu campus, Brazil; assistant in administration at the Federal University of Latin American Integration, State of Paraná, Brazil. E-mail: jo4medeiros@gmail.com.

${ }^{6} \mathrm{PhD}$ in Mathematical Education, Paulista State University Júlio de Mesquita Filho, Rio Claro campus, State of São Paulo, Brazil; adjunct professor at the State University of Western Paraná, Foz do Iguaçu campus, State of Paraná, Brazil. E-mail: marcoslubeck@gmail.com.

${ }^{7}$ Master in Teaching, State University of Western Paraná, Foz do Iguaçu campus, Brazil; teacher at the state education network in Foz do Iguaçu, State of Paraná, Brazil. E-mail: graciela.siegloch@gmail.com.

${ }^{8}$ Master in Teaching, State University of Western Paraná, Foz do Iguaçu campus; teacher at the municipal education network in Foz do Iguaçu, State of Paraná, Brazil. E-mail: fernando_andretti@ hotmail.com. 


\section{Palavras iniciais}

Nos primeiros anos da década de 1960, um projeto de Paulo Freire denominado Círculos de Cultura intencionava alfabetizar adultos, trabalhadores, cidadãos brasileiros, a partir da valorização dos seus conhecimentos cotidianos. Nessa dinâmica, o grupo de aprendizes elegia algumas palavras oriundas da sua realidade, do seu universo vocabular, as quais eram chamadas de palavras geradoras, ou temas geradores, pois cada palavra escolhida gerava outras tantas palavras, e também outros temas, aumentando assim o número de palavras que passavam a ser conhecidas e ainda por conhecer. Nisso, os temas eram problematizados, instigando as pessoas a pensarem e a discutirem sobre a sua condição de vida, a sua sobrevivência e transcendência, e a sua presença no mundo.

Nesses termos,

mais do que um ser no mundo, o ser humano se tornou uma presença no mundo, com o mundo e com os outros. Presença que, reconhecendo a outra presença como um "não-eu" se reconhece como "si própria". Presença que se pensa a si mesma, que se sabe presença, que intervém, que transforma, que fala do que faz, mas também do que sonha, que constata, compara, avalia, valora, que decide, que rompe. (FREIRE, 1996, p. 20).

A história da educação brasileira mostra que a intenção, na época, era expandir o projeto inspirado nos temas geradores do exemplo citado para todo o país, fazendo uma alfabetização conscientizadora e problematizadora, pois algo em torno da metade da população daquele tempo era analfabeta e, portanto, encontrava-se tolhida de muitos direitos. A sua alfabetização representaria um avanço na educação e contribuiria para as pessoas alfabetizadas serem agentes mais ativos nas ações de transformação do mundo.

Os participantes do "círculo de cultura", em diálogo sobre o objeto a ser conhecido e sobre a representação da realidade a ser decodificada, respondem às questões provocadas pelo coordenador do grupo, aprofundando suas leituras do mundo. O debate que surge daí possibilita uma releitura da realidade, de que pode resultar o engajamento do alfabetizando em práticas políticas com vista à transformação da sociedade. (FREIRE, A., 1996, p. 38).

Entretanto, com a Ditadura Militar, o projeto foi interrompido e Paulo Freire exilado em 1964, segundo Gadotti (1996, p. 72), “porque a Campanha Nacional de Alfabetização no Governo de João Goulart estava conscientizando imensas massas populares que incomodavam as elites conservadoras brasileiras". De fato, “a educação das massas se faz, 
assim, algo de absolutamente fundamental entre nós. Educação que, desvestida da roupagem alienada e alienante, seja uma força de mudança e de libertação" (FREIRE, 2007, p. 44). Em contrapartida, no lugar desse projeto foi inserido o Movimento Brasileiro de Alfabetização (MOBRAL), que empregava também palavras geradoras, porém definidas pela equipe técnica do governo.

Com isso, a intenção era tão-somente alfabetizar, sem a preocupação com uma alfabetização que proporcionasse a criticidade aos educandos. Enquanto que, no caso do método de Paulo Freire, a alfabetização tinha como objetivo também preparar o aluno não simplesmente para viver a sociedade como ela é, mas para propiciar a ele criticidade para transformar a sociedade. Uma mudança de postura tanto do aluno como do profissional que atua com ele, pois "não há docência sem discência, [...] quem ensina aprende ao ensinar e quem aprende ensina ao aprender" (FREIRE, 1996, p. 25).

A ideia básica do Método Paulo Freire é a adequação do processo educativo às características do meio [...]. As palavras geradoras selecionadas giram em torno de 17 [...]. Cada uma dessas palavras era dividida em sílabas; estas eram reunidas em composições diferentes, formando novas palavras. A discussão das situações sugeridas pelas palavras geradoras permitia que o indivíduo se conscientizasse da realidade em que vivia e da necessidade da sua participação na transformação dessa mesma realidade, tornando mais significativo e eficiente o processo de alfabetização. Era o próprio adulto que se educava, orientado pelo coordenador de debates (o professor), mediante a discussão de suas experiências de vida com outros indivíduos que participavam das mesmas experiências. (PILETTI; PILETTI, 2012, p. 202).

Para Freire, desse modo, o educando deixa de ser passivo, receptor de uma educação bancária, em que, segundo Gadotti (1996), predominam as relações narradoras e dissertadoras, e a educação não passa de um ato de depositar (como nos bancos); isto é, “[...] os educandos são depositários e o educador depositante. [...] nessa distorcida visão de educação, não há criatividade, não há transformação [...]. Na visão 'bancária' da educação, o 'saber' é uma doação dos que se julgam sábios aos que julgam nada saber" (FREIRE, 2008, p. 67). Contrário a isso, o educando assume uma postura mais prática, mais ativa e mais consciente de seu papel dentro do processo do ensinar e do aprender, características necessárias para alguém desenvolver sua autonomia (FREIRE, 1996).

Com a Lei $n^{\circ}$ 12.612, de 13 de abril de 2012, Paulo Freire foi declarado Patrono da Educação Brasileira. E isso serviu como incentivo para ampliar o reconhecimento e a divulgação nas escolas do método Paulo Freire. Observe que ele defendia uma educação crítica, no qual o educando deve ser um participante do processo, e não queria que a educação 
fosse bancária, opressora, impositiva e unilateral, em que um professor deposita informações nas cabeças passivas dos alunos (FREIRE, 2007; 2008).

Contudo, em 11 de outubro de 2017, foi apresentada à Comissão de Direitos Humanos e Legislação Participativa (CDHLP) do Senado Federal, a Sugestão no 47 de 2017, em que se solicitava a revogação da Lei $n^{\circ} 12.612 / 2012$. Segundo os defensores, Paulo Freire seria um filósofo de esquerda e seu método de educação estaria baseado no sócio construtivismo, que seria a materialização do marxismo. A sugestão foi rejeitada pela dita comissão, e assim a tramitação foi encerrada em 22 de dezembro daquele ano. Porém, desde 2019, com a ascensão ao Palácio do Planalto, ao Congresso Nacional e ao Senado Federal de políticos com orientações divergentes às defendidas por Paulo Freire, este educador voltou a ser atacado.

Controvérsias à parte, o fato é que a teoria de Paulo Freire já se mostrou válida e comprovada em muitos aspectos e em diversas áreas do conhecimento. Por essa razão também foi retomada aqui, para a disciplina de Matemática, em particular para um tema que envolve educação financeira e fiscal, algo real, prático e imprescindível atualmente.

\section{Matemática e Pedagogia da Autonomia: saberes necessários à prática educativa}

Infelizmente, não é raro ouvir lamentações sobre sentimentos pouco amistosos pela Matemática (MEDEIROS, 2019). Desde muito tempo, parece que os conteúdos matemáticos permanecem insistentemente ligados a métodos e algoritmos ensinados de forma mecanizada, em que é dada essa disciplina como pronta e acabada, e que, uma vez apresentados os conceitos e conteúdos, são sobrepostos a eles uma série de exemplos, e posteriormente, exercícios de fixação, não havendo muita preocupação em desenvolver o pensamento lógico que concatena os conceitos. Isso diverge de um dos saberes necessários à prática pedagógica de Paulo Freire, de que ensinar exige consciência do inacabamento, e para quem "ensinar não é transferir conteúdo a ninguém, assim como aprender não é memorizar o perfil do conteúdo transferido no discurso vertical do professor" (FREIRE, 1996, p. 134).

Nesse âmbito, apenas transferir conhecimento ao educando não produz uma aprendizagem de fato, efetiva e significativa, pois, muitas vezes, por meio das respostas dadas aos exercícios, o aprendiz demonstra que decorou o conteúdo, e uma vez contextualizado o exercício de uma forma diferente, o aluno nos surpreende com erros, evidenciando não ter aprendido verdadeiramente. 
Que me seja perdoada a reiteração, mas é preciso enfatizar, mais uma vez: ensinar não é transferir a inteligência do objeto ao educando, mas instigá-lo no sentido de que, como sujeito cognoscente, se torne capaz de inteligir e comunicar o inteligido. É nesse sentido que se impõe a mim escutar o educando em suas dúvidas, em seus receios, em sua incompetência provisória. E ao escutá-lo, aprendo a falar com ele. (FREIRE, 1996, p. 134135).

Escutar o que o educando tem a dizer, tratá-lo de forma humanizada, não apenas como mais um número na lista de controle de frequência, também é "testemunhar a abertura aos outros, a disponibilidade curiosa à vida, a seus desafios, [estes] são saberes necessários à prática educativa" (FREIRE, 1996, p. 153), seja em qual for a disciplina. É importante que o professor dialogue com o aluno para saber o que ele já sabe sobre os conteúdos e para saber sua experiência pessoal com a Matemática, possibilitando assim sanar dúvidas e defasagens, para não gerar incompreensões sobre conteúdos mais aprofundados. Para além disso, que abra escutas para conhecer quem é cada aluno, sua leitura de mundo, as experiências, as expectativas, as condições socioeconômicas e socioculturais dos mesmos, pois "não é possível respeito aos educandos, [...] se não se reconhece a importância dos 'conhecimentos de experiência feitos' com que chegam à escola" (FREIRE, 1996, p. 71). Nesse viés, alinhamse alguns dos princípios sobre docência de Paulo Freire (1996), a saber, que ensinar exige curiosidade, saber escutar, disponibilidade para o diálogo, respeito aos saberes dos educandos e querer bem aos educandos.

Importante também é tornar a Matemática menos temida, desmistificá-la, torná-la acessível a ponto de os educandos entenderem que essa ciência é parte integrante de sua vida, que desde o acordar e o olhar no relógio, e se programar para ir à escola, por exemplo, está se usando a Matemática, embora sem ter a consciência precisa dessa utilização. Daí pode surgir, então, uma práxis vital, transformadora, a partir de

uma preocupação fundamental, não apenas dos matemáticos mas de todos nós, sobretudo dos educadores, a quem cabe certas decifrações do mundo [...]: a de propor aos jovens, estudantes, alunos homens do campo, que antes e ao mesmo tempo em que descobrem que 4 por 4 são 16 , descobrem também que há uma forma matemática de estar no mundo. (D’AMBRÓSIO, 1999, p. 1-2).

Da mesma forma, é interessante vincular os conteúdos matemáticos escolares com os acontecimentos, os saberes e fazeres do cotidiano, trabalhando atividades dos contextos dos educandos para que eles percebam que aprender Matemática não é apenas privilégio para uma 
minoria excepcional, mas que ela pode ser acessível a todos e que é extremamente necessário e útil conhecê-la bem.

Os conteúdos escolares, para serem mais significativos, devem descentralizar os sentidos em torno de si mesmos, e proporcionar aos educandos entender sua utilização na vida em sociedade, para eles não incorrerem no que diz Freire (1996, p. 29-30):

O intelectual memorizador, que lê horas a fio, domesticando-se ao texto, temeroso de arriscar-se, fala de suas leituras quase como se estivesse recitando-as de memória - não percebe, quando realmente existe, nenhuma relação entre o que leu e o que vem ocorrendo no país, na sua cidade, no seu bairro.

Nesse aspecto, não basta simplesmente ensinar os conteúdos matemáticos dentro do contexto envolvente do educando, mas é necessário problematizar tais conteúdos nas relações sociais, culturais, políticas e econômicas, de modo a propiciar "a capacidade de aprender, não apenas para nos adaptar, mas sobretudo para transformar a realidade, para nela intervir, recriando-a" (FREIRE, 1996, p. 76). Assim, instigar os educandos a discutirem sobre sua realidade e o que acontece no mundo (corrupção, injustiças sociais, violência etc.), refletindo especialmente sobre a sua condição de vida na sociedade, é fundamental, para que eles percebam que pelo conhecimento é possível intervir no mundo.

Nesse sentido, alinham-se outros princípios sobre docência de Freire (1996): de que ensinar exige criticidade, a corporificação das palavras pelo exemplo, a tomada consciente de decisões, a reflexão crítica sobre a prática, a apreensão da realidade, a convicção de que a mudança é possível, e a compreensão de que a educação é uma forma de intervenção do mundo.

Por meio dos conteúdos escolares é possível saber, até certo ponto, que tipo de cidadão o sistema escolar pretende formar. De fato:

Não há como negar isso e basta um estudo mais cuidadoso para se reconhecer, na maneira como se ensina e no próprio conteúdo do que se ensina, o interesse das classes dominantes, que continuam mesquinhas e com poder crescente! O discurso agora é mais preciso, tem havido um aperfeiçoamento de argumentos e até a racionalização de práticas que continuam opressivas e desumanas. Alguns sugerem que é normal haver excluídos numa sociedade. (D’AMBROSIO, 1999, p. 38).

Observe que o sistema escolar deveria prezar pela formação de um educando como cidadão crítico e desenvolver sua capacidade de autonomia de ação e reflexão na realidade. 
No entanto, ainda está impregnada de interesses de ideologias dominantes, ou seja, faz com que não seja questionada a realidade que aí está, aquela em que se vive da forma como ela se apresenta, sem questionar e sem tentar transformá-la. Nesse caso, resta ao educando sobreviver à realidade como ela lhe é posta, num contínuo estado de conformação e letargia, mantendo assim a situação atual. E aqui cabe uma ressalva:

Creio que nunca precisou o professor progressista estar tão advertido quanto hoje em face da esperteza com que a ideologia dominante insinua a neutralidade da educação. Desse ponto de vista, que é reacionário, o espaço pedagógico, neutro por excelência, é aquele em que se treinam os alunos para práticas apolíticas, como se a maneira humana de estar no mundo fosse ou pudesse ser uma maneira neutra. (FREIRE, 1996, p. 109-110).

Dessa forma, reconhecer que a educação é libertadora, uma ferramenta de transformação para o cidadão, uma forma de intervenção no mundo, torna-se cada dia mais imprescindível, e isso integra princípios sobre docência de Paulo Freire (1996). Note que, se educando e educador tiverem consciência da dominação que é exercida sobre eles, a partir dessa consciência, eles poderão fazer as mudanças tão necessárias.

\section{Aplicação de uma atividade matemática utilizando a teoria de Paulo Freire}

A intenção foi colocar em prática uma atividade matemática utilizando a teoria de Paulo Freire, para uma turma de $5^{\circ}$ ano do Ensino Fundamental I, de uma escola municipal de Foz do Iguaçu, Paraná. A atividade foi aplicada na Escola Municipal Olavo Bilac, com uma turma $^{9}$ do vespertino, com a duração de 2 h10min de aula. A turma era composta por 25 alunos, com idades entre 10 e 12 anos. Na escola há aproximadamente 220 alunos matriculados e a maioria deles reside em comunidades próximas, compostas majoritariamente por trabalhadores assalariados e de baixa renda. A metodologia adotada seguiu alguns preceitos da pesquisa-ação.

A pesquisa-ação é um tipo especial de pesquisa participante, em que o pesquisador se introduz no ambiente a ser estudado não só para observá-lo e compreendê-lo, mas, sobretudo, para mudá-lo em direções que permitem a

\footnotetext{
${ }^{9}$ Para a divulgação de imagens e falas dos participantes na pesquisa, há a autorização dos responsáveis pelos participantes.
} 
melhoria das práticas e maior liberdade de ação e de aprendizagem dos participantes. Ou seja, é uma modalidade de atuação a observação centrada na reflexão-ação. Apresenta-se como transformadora, libertadora [...]. Tratase de um processo investigativo em que caminham juntas prática investigativa, prática reflexiva e prática educativa. (FIORENTINI; LORENZATO, 2006, p. 112).

A análise dos dados foi qualitativa, e de acordo com Bodgan e Biklen (1999, p. 232), "sempre que fazemos análises somos, usualmente, parte do diálogo acerca do tópico que estamos a considerar. [...] a análise é moldada pelas perspectivas e posições teóricas do investigador e pelas ideias que ele partilha acerca do assunto". Nesse sentido, "o processo de análise e interpretação é fundamentalmente iterativo, pois o pesquisador elabora pouco a pouco uma explicação lógica do fenômeno ou da situação estudada” (GIL, 2002, p. 90). Assim, para organizar e interpretar os dados coletados, selecionam-se episódios, de modo a confrontar ou aproximar essas informações obtidas em relação à visão teórica.

Essa análise é feita a partir da teoria já bem fundamentada no marco teórico do objeto de estudo. [...]. Nesse processo, o pesquisador(a) vai fazendo sua análise, podendo citar ou não pequenos trechos de autores que dão sustentação teórica à pesquisa. É preciso entender que não se faz necessário estar realizando novamente uma construção teórica através da análise do pensamento dos autores(as), pois neste momento, ao analisar os dados, o pesquisador(a) é que deve construir sua teoria. Quando se reporta a um determinado autor(a) já trabalhado na fundamentação teórica deve, então, fazê-lo ser de forma rápida apenas para dar maior sustentação ao processo de análise. (OLIVEIRA, 2016, p. 103-104).

Antecipadamente, foi conversado com a professora regente da turma para que solicitasse aos alunos que trouxessem um cupom fiscal de compras efetuadas (mercado, farmácia, posto de combustível etc.) no dia da realização da atividade. Como primeira atividade foi solicitado aos alunos que preenchessem um questionário. Nele, havia dez palavras das quais os alunos deveriam destacar (pintar) as que não sabiam o que significavam. $\mathrm{Na}$ sequência, eles deveriam escrever lugares ou situações em que usavam a Matemática no seu dia a dia, além de escrever se gostavam ou não de Matemática, como pode ser visto no exemplo da Figura 1. 
Figura 1 - Exemplo de um questionário respondido

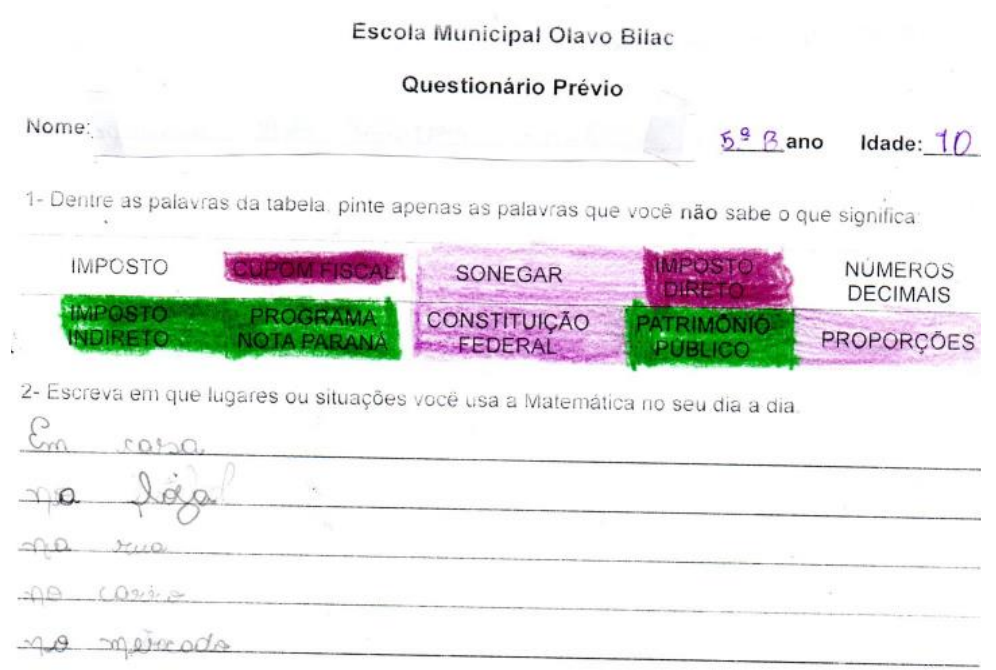

Fonte: Os autores (2019).

Participaram da aula, nesse dia, 20 alunos, sendo 11 meninos e 9 meninas. Dos 20 alunos, 13 responderam que gostam de Matemática, 3 responderam que não gostam e 4 responderam que gostam mais ou menos de Matemática. Ao escreverem os lugares ou situações em que a usam no seu dia a dia, as palavras mais citadas foram as seguintes: dinheiro, padaria, pizzaria, comida, bebida, mercado, feira, shopping, carro, loja, sorveteria. Essas palavras remetem a compras e, consequentemente, uma relação com o cupom físcal. No caso, corroborou a sugestão da palavra norteadora proposta inicialmente, em que se propôs o uso do cupom fiscal como meio articulador de conteúdos matemáticos escolares e contextualização com algo da realidade do aluno. Além disso, outras palavras citadas foram: casa, banco, futebol, jogos, celular, casa de parentes, receitas, conta de luz e água, entre outras. Quanto às dez palavras do questionário, foi solicitado que destacassem as que não sabiam o significado, sendo que as palavras mais destacadas foram: sonegar, imposto indireto, Constituição Federal, patrimônio público, Programa Nota Paraná, imposto direto e proporção. Essas palavras geradoras não foram reunidas necessariamente para alfabetizar os educandos, pois eles já estão adiantados no processo de alfabetização, mas para conscientizá-los e para problematizar a sua realidade. A Figura 2 mostra a sala de aula durante a aplicação do questionário. 
Figura 2 - Aplicação do questionário na sala de aula

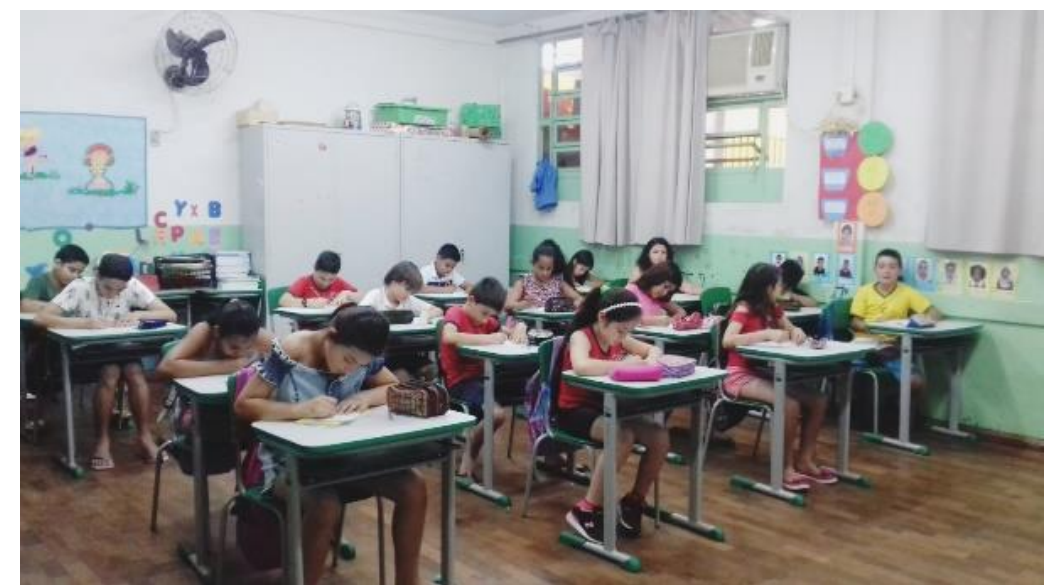

Fonte: Os autores (2019).

Após o questionário, foi sugerido aos alunos sentarem em círculo, porém eles preferiram ficar em seus lugares. Assim, iniciamos um diálogo, comentando sobre cada palavra apresentada no questionário e descrevendo ligações dessas palavras com a Matemática. Nessa etapa, quando se falou da palavra "imposto", os alunos mencionaram o seguinte: "Quando a gente compra uma coisa e paga R \$50,00, e em vez disso, tem que pagar um pouco mais, estamos pagando imposto"; "Quando os vereadores embolsam dinheiro"; "Eu sei que o IPVA é um imposto, porque meu irmão não pagou e a polícia recolheu o carro dele”. "Meu pai não vota e sempre paga multa porque não vota".

Aqui, foi dialogado sobre a finalidade da cobrança de impostos, que devem retornar aos cidadãos em forma de serviços públicos; a importância de não sonegar impostos, pois é menos dinheiro para o investimento em saúde, educação, segurança etc.; as formas como são cobrados os impostos, direta e indiretamente; e que os impostos indiretos acabam sendo inversamente proporcionais, ou seja, regressivos, em que os mais pobres são os que acabam pagando mais impostos, isso porque praticamente metade do total de impostos arrecadados no Brasil são impostos por bens e serviços, ou seja, tributos indiretos (LIMA, 2014).

O objetivo do diálogo foi conversar sobre o que os alunos sabiam sobre as palavras, e fazê-los refletirem relacionando seus saberes com as conceituações formais das palavras, pois "é a maneira correta que tem o educador de, com o educando e não sobre ele, tentar a superação de uma maneira mais ingênua por outra mais crítica de inteligir o mundo" (FREIRE, 1996, p. 138, grifo no original). 
Partindo da palavra lei, instigando-os até chegarem ao entendimento que existem documentos que estabelecem normas para vivermos em harmonia na sociedade, o que remeteu à palavra/expressão "Constituição Federal”.

Após o diálogo para conceituar as palavras, foi realizada uma dinâmica com a finalidade de verificar o entendimento dos alunos quanto às palavras citadas no diálogo. Foi pedido aos alunos para olharem embaixo de suas cadeiras, pois lá havia uma surpresa. Os alunos ficaram admirados com o achado, como mostra a Figura 3.

Figura 3 - Alunos encontrando as palavras e definiç̧ões

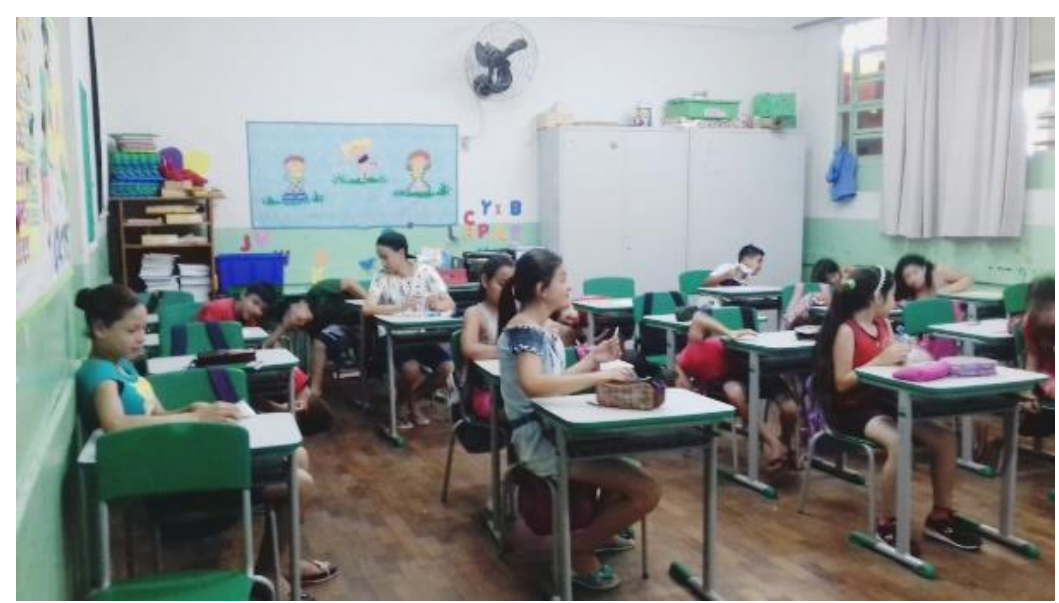

Fonte: Os autores (2019).

Embaixo da cadeira havia um papel com um bombom. Alguns papéis continham as palavras imposto, imposto indireto, cupom fiscal, Programa Nota Paraná, sonegar, Constituição Federal, imposto direto, patrimônio público, proporção e números decimais, e em outros os seus significados. O educando que pegou o papel com a definição da palavra lia em voz alta e todos ajudavam a identificar a qual ele estava se referindo. Os que estavam com a tal palavra juntavam-se com a pessoa que estava lendo a definição, e assim formavam duplas ou trios, como pode ser visto na Figura 4. Nessa atividade, todos colaboraram e juntos conseguiram associar as definições com suas respectivas palavras. 
Figura 4 - Alunos realizando a atividade

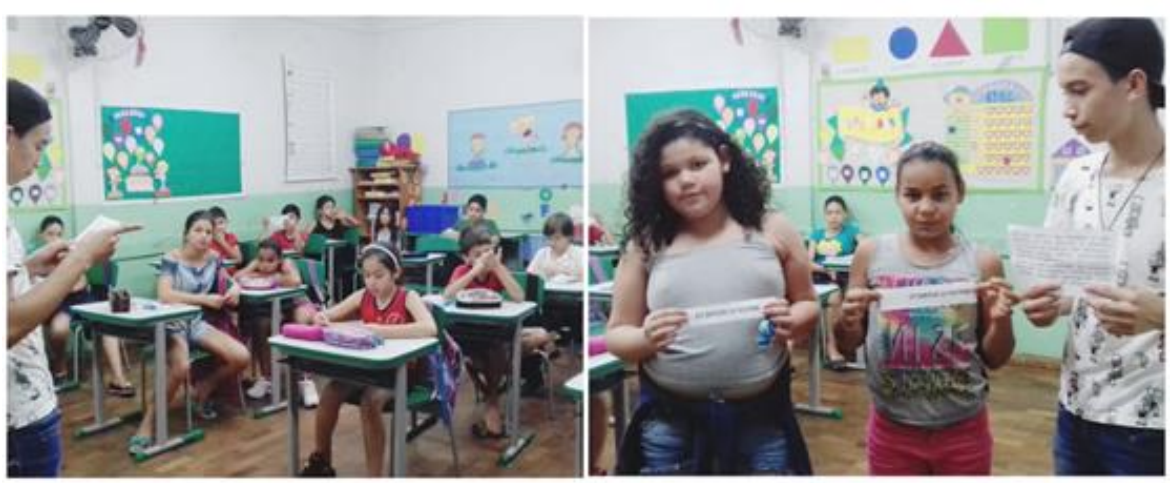

Fonte: Os autores (2019).

Formados as duplas e os trios, começou o trabalho. A maioria dos alunos trouxe seu cupom fiscal, e para os que não trouxeram foi disponibilizado um. Em princípio, foi realizada uma leitura minuciosa do cupom fiscal, dando ênfase à localização do valor total da compra e os tributos.

Muitos ficaram surpresos em saber que ali constava o valor do tributo, dizendo que não costumavam olhar os cupons e que ou o jogavam fora ou nem pediam no momento da compra. Analisando o cupom, os alunos concluíram que há muita Matemática ali, que os números decimais são bem visíveis e que podemos somar as compras de maneira manual, mas que isso dá muito trabalho.

Como atividade, foi pedido para eles destacarem o local dos tributos e somarem, pois estavam separados em federais e estaduais. Cada aluno marcou a soma de seu tributo na lousa. Resolveram somar todos os tributos para verem quanto pagavam de impostos ali na sala com aquelas compras efetuadas nos cupons. Antes disso, foi solicitado aos alunos anotarem em uma folha quanto achavam que seria o resultado de toda a soma do tributo.

Assim, para somar todos os tributos, em vez de uma única vez, a soma foi reduzida em várias, logo, foi pedido que cada aluno viesse na lousa e somasse de dois em dois. Assim, somados todos os tributos, o resultado foi de $\mathrm{R} \$ 329,11$ (que eles disseram ser muito dinheiro). Dois alunos colocaram valores aproximados, $\mathrm{R} \$ 300,00$ e $\mathrm{R} \$ 345,20$, ao anotarem quanto achavam que timham gasto em tributos naqueles cupons.

Foi pedido paradestacarem o valor total da compra, e em seguidas súbtrair os tributos desse total. Dessa forma, observaram gue pagariam bẹm menos senão tivessem os impostos embutidos nas compras. Ao questena os annos como somâr e subtrair números decimais, foi possível constatar the eles sabiancaterlat, apenas um tinha dificuldade com a vírgula. 
Depois, foi explicada para a classe a importância de saber Matemática para inspecionar as compras efetuadas, enfatizando o ato de ler atentamente o cupom fiscal e entendê-lo. Foi solicitado, ainda, para falarem quem tinha a maior e menor compra, para daí fazer a comparação dos valores dos cupons, além de comparar seus tributos. A intenção foi problematizar que tanto uma pessoa que recebe um salário alto quanto uma pessoa de baixa renda pagam o mesmo valor de impostos, na mesma compra efetuada. Só que o tal imposto é um valor bem mais significativo no salário da pessoa de baixa renda.

Nesse tipo de imposto, caracterizado como indireto, pessoas com menos condições econômicas pagam, proporcionalmente à sua renda, mais tributos que as pessoas mais ricas. Uma aluna fez o seguinte apontamento: "pessoas de alta renda geralmente compram produtos de marcas melhores e bem mais caras, que a gente pobre não consegue comprar." Apontamento relevante, pois nesse tipo de imposto, muitos produtos acabam sendo difíceis, se não impossíveis, de serem comprados por pessoas de baixa renda. As "maneiras de calcular impostos, auxílio às crianças, salários, estratégias de produção etc. não são apenas modelos de pensamento, elas têm uma influência real nas nossas vidas" (SKOVSMOSE, 2001, p. 81).

Em suma, foi possível identificar com essa aplicação de atividade que os alunos, apesar de inicialmente não saberem os significados das palavras apresentadas, possuíam alguns conhecimentos sobre a temática dos impostos, e por meio do diálogo, foi possível relacionar seus conhecimentos ainda ingênuos com as palavras e as definições formais.

A atividade aplicada favoreceu o desenvolvimento e o exercício da autonomia dos educandos, sendo que tal autonomia foi praticada por meio do diálogo com a professora e os demais colegas, e não como simples transferência de conhecimento da professora para os alunos. Importa lembrar que aplicar esporadicamente esse tipo de atividade não é suficiente, uma vez que se faz necessário estimular outras situações e vivências para que, gradativamente, os estudantes se tornem autônomos, pois a autonomia não acontece em data e hora marcada, mas "tem que estar centrada em experiências estimuladoras da decisão e da responsabilidade, vale dizer, em experiências respeitosas da liberdade" (FREIRE, 1996, p. 121).

Os questionamentos levantados pelos alunos foram coerentes, demonstrando que eles sabiam que a finalidade dos impostos é gerir os serviços públicos, mas que, infelizmente, pela má-fé de alguns governantes, muitos impostos não são revertidos em serviços. Por isso "temos de fazer uma distinção entre a competência que os governantes devem possuir para tomar decisões [...] e a competência que supostamente as pessoas precisam ter para julgar os 
resultados e as consequências do governar" (SKOVSMOSE, 2001, p. 73). Nesse sentido, então, "a educação deve preparar os alunos para uma vida (política) na sociedade" (SKOVSMOSE, 2001, p. 87), o que foi possível observar por meio da atividade quanto ao pensamento crítico desenvolvido pelos alunos quando foi tratado de um tema de sua realidade.

\section{Considerações finais}

Conteúdos ensinados de forma mecanizada não produzem aprendizagem efetiva no educando, apenas reproduzem ensinamentos que eles, por vezes, não conseguem compreender, relacionar e utilizar no seu contexto social. Nesse sentido, os saberes necessários à prática educativa do livro Pedagogia da Autonomia de Paulo Freire proporcionou uma reflexão profunda sobre ensinar e aprender. Segundo o autor, o professor deve ocupar uma posição horizontal no processo de ensino e aprendizagem, possibilitando o diálogo com os alunos e não a simples transferência de conhecimento.

Aliás, nesse aspecto, o professor é uma pessoa que pode estimular o educando a desenvolver sua autonomia. “A autonomia vai se constituindo na experiência de várias, inúmeras decisões, que vão sendo tomadas. [...]. A autonomia, enquanto amadurecimento do ser para si, é processo, é vir a ser. Não ocorre em data marcada" (FREIRE, 1996, p. 121).

A atividade proporcionou um pequeno avanço na autonomia dos educandos, uma vez que não existe aumento drástico da autonomia, pois o exercício da autonomia, nos dizeres de Freire, é desenvolvido por meio de um processo. Nesse aspecto, a atividade aplicada se mostrou como uma experiência estimuladora, apresentando-se como um ponto inicial para o processo da autonomia. Propiciou uma situação de aprendizagem mostrando a importância do cupom fiscal e sua leitura crítica.

A autonomia do educando foi exercitada por meio do diálogo estabelecido entre os alunos e a posição horizontal da professora, desafiando os alunos a pensarem criticamente a realidade social e política. Eles foram estimulados a problematizar que, por meio da educação, é possível mudar as situações e ações das pessoas, entendendo como funciona a sociedade e o que é preciso para manter os serviços públicos, propiciando conhecimentos para fiscalizar e cobrar os governantes.

Por meio da realização da atividade, pode-se perceber que os alunos possuíam noção da maioria das palavras utilizadas no questionário, ou seja, apresentavam conhecimentos 
básicos sobre a temática. Com a execução da atividade foi possível relacionar esses conhecimentos com as definições formais das palavras, além de mostrar que para tais conhecimentos havia termos específicos para designá-las. Também foi possível instigá-los a refletirem sobre o uso da Matemática no seu cotidiano, e sobre a injustiça social no que se refere a impostos, fornecendo assim subsídios para um olhar crítico sobre sua realidade.

Isto posto, é importante trabalhar conteúdos matemáticos escolares de forma que os educandos compreendam sua aplicação fora da escola, vinculando-os com a realidade social. Reafirmando a teoria de Freire, o estudo mostra que, para além de trabalhar a Matemática do cotidiano, sejam considerados os saberes e fazeres dos educandos, seus conhecimentos e a necessidade da problematização das temáticas trabalhadas; que o professor levante questões que conduzam o educando a ter um pensamento mais crítico, a questionar sua realidade, reconhecendo-se como agente de transformação do mundo, e que uma realidade desigual deve ser transformada para uma realidade de igualdade.

Enfim, somente com uma educação que busque desenvolver a consciência crítica é que os alunos poderão exercer, de fato, sua cidadania, utilizando os conhecimentos matemáticos adquiridos... Até porque, no mundo do adulto analfabeto, ou semianalfabeto, numa fila em busca do emprego, não há cadeiras com bombons embaixo do assento e nem se distribuem doces. Tampouco há isso no mundo de pessoas alfabetizadas, afinal estamos vivenciando uma taxa de desemprego altíssima, inclusive para pessoas com ensino superior e pós-graduação. Logo, a educação crítica contribui a uma reflexão dos sujeitos para pensar numa sociedade menos injusta, mais solidária, com uma compreensão de que as coisas não são assim, elas estão assim e por isso mesmo podem ser mudadas para o bem comum.

\section{Referências}

BODGAN, R. C.; BIKLEN, S. K. Investigação qualitativa em educação: uma introdução à teoria e os métodos. Porto: Porto, 1999.

BRASIL. Lei ${ }^{\circ}$ 12.612/2012, de 13 de abril de 2012. Declara o educador Paulo Freire Patrono da Educação Brasileira. Brasília: MEC, 2012. Disponível em: http://www.planalto.gov.br/ccivil_03/_ato2011-2014/2012/lei/112612.htm. Acesso em: 4 dez. 2019.

D’AMBROSIO, U. A história da matemática: questões historiográficas e políticas e reflexos na educação matemática. In: BICUDO, M. A. V. (org.). Pesquisa em educação matemática: concepções e perspectivas. São Paulo: Editora da UNESP, 1999. p. 97-115. 
FIORENTINI, D.; LORENZATO, S. Investigação em educação matemática: percursos teóricos e metodológicos. Campinas: Autores Associados, 2006.

FREIRE, P. Educação como prática da liberdade. 30. ed. Rio de Janeiro: Paz e Terra, 2007.

FREIRE, P. Pedagogia da autonomia: saberes necessário à prática educativa. São Paulo: Paz e Terra, 1996.

FREIRE, P. Pedagogia do oprimido. 47. ed. Rio de Janeiro: Paz e Terra, 2008.

FREIRE, A. M. A. A voz da esposa: a trajetória de Paulo Freire. In: GADOTTI, M. Paulo

Freire: uma bibliografia. São Paulo: Cortez/Instituto Paulo Freire, 1996. p. 27-68.

GADOTTI, M. A voz do biógrafo brasileiro: a prática à altura do sonho. In: GADOTTI, M. Paulo Freire: uma bibliografia. São Paulo: Cortez/Instituto Paulo Freire, 1996. p. 69-115.

GIL, A. C. Como elaborar projetos de pesquisa. 4. ed. São Paulo: Atlas, 2002.

LIMA, B. P. Tributos indiretos oneram os mais pobres e tiram competitividade do país. $\mathbf{O}$ Estado de S. Paulo. 23 maio 2014. Disponível em:

https://economia.estadao.com.br/noticias/geral,tributos-indiretos-oneram-os-mais-pobres-etiram-competitividade-do-pais-imp-,1170528. Acesso em: 4 dez. 2019.

MEDEIROS, J. A aversão à matemática no olhar dos professores licenciados em matemática da rede municipal de ensino de Foz do Iguaçu/PR. 2019. 155 f. Dissertação (Mestrado em Ensino) - Universidade Estadual do Oeste do Paraná, Foz do Iguaçu, 2019.

OLIVEIRA, M. M. de. Como fazer pesquisa qualitativa. 7. ed. Petrópolis: Vozes, 2016.

PILETTI, C.; PILETTI, N. História da educação: de Confúcio a Paulo Freire. São Paulo: Contexto, 2012.

SKOVSMOSE, O. Educação matemática crítica: a questão da democracia. Campinas, SP: Papirus, 2001.

SUGESTÃO n 47, de 2017. Brasília: Senado Federal, 2017. Disponível em: https://www25.senado.leg.br/web/atividade/materias/-/materia/131196/pdf. Acesso em: 4 dez. 2019.

Submetido em 2 de janeiro de 2020.

Aprovado em 14 de abril de 2020. 